\title{
TaskForce Tarmed
} SGUM

Seit der Einführung der Verrechenbarkeit des Seitenvergleichs bei paarigen Extremitäten-Untersuchungen (unter bestimmten Voraussetzungen) ist es wieder ruhig geworden. Vereinzelte Versicherer haben den am 1.5.2013 publizierten PIKEntscheid zu diesem Thema offenbar noch nicht zur Kenntnis genommen und müssen darauf aufmerksam gemacht werden. Wer jetzt noch Probleme hat mit Rückweisungen melde sich bitte bei mir. Hier meine neue Adresse: Sonografie-Institut Glattpark GmbH, Thurgauerstr. 105, 8152 Zürich-Glattpark, e-mail: beat.dubs@sono-glattpark.ch

Beat Dubs 